\title{
Inhibition effects of Gorge Fischer plumbing system on growth and amplification of Legionella Pneumophila with culture and PCR based on 16sRNA and mip genes
}

\section{Leila Barzegar}

Azad University: Islamic Azad University

Ghader Ghanizadeh

Baqiyatallah University of Medical Sciences

Davoud Esmaeili ( $\square$ esm114@gmail.com )

BMSU https://orcid.org/0000-0001-9632-4058

\section{Research}

Keywords: Legionella, George Fischer Piping, Rey Ho, mip gene, 16SrRNA

Posted Date: September 21st, 2021

DOI: https://doi.org/10.21203/rs.3.rs-880123/v1

License: (9) This work is licensed under a Creative Commons Attribution 4.0 International License.

Read Full License 


\section{Abstract \\ Background}

Legionella is an aquatic bacterium that causes Legionnaires' fever.

\section{Methods}

Fifty-six samples of the hot and cold-water system were collected. Characteristics of water samples were measured. Culture was performed in BCYE agar. Molecular identification was performed by PCR.

\section{Results}

The mean residual chlorine were 0.73 to $0.88 \mathrm{mg} /$ I. Culture results were positive $58.8 \%$ of George Fischer and $23.5 \%$ of Ray Ho and $60 \%$ Taleghani hospital samples. PCR results based on 16 sRNA were $35.2 \%$ of the George Fischer system, 45.4\%, from Ray Ho piping and 54.5\% from Taleghani hospital. the results of the mip gene, $82.3 \%$ of George Fischer, $54.5 \%$ of RayHo and $20 \%$ of Taleghani hospital were positive.

\section{Conclusion}

George Fischer's Legionella stopper pipes and fittings have a good ability to control the growth Legion density in the indoor water supply system and can be considered as a suitable option for use in indoor plumbing and water supply.

\section{Introduction}

With the increase in population, the improvement of living standards, followed by the increase in water consumption and the decrease in water resources, and the increase in physical, chemical, and microbial pollution of water, the water crisis has become one of the major global problems. The most water-related concerns are in arid and semi-arid regions and more than $80 \%$ of diseases worldwide are water-based diseases (1).

According to the World Health Organization and UNICEF (WHO / UNICEF), approximately 1.1 billion people worldwide do not have access to adequate drinking water resources, and 5.2 billion people who have access to adequate and safe water resources are polluted along the way. Water transfer and water distribution systems have prevented this number from using safe drinking water. In Europe, it is estimated that 120 million Europeans do not have access to safe and secure water (2). Also, according to the World Health Organization, 2.4 million out of 4 billion cases of diarrhea are due to a lack of access to safe drinking water (3). Every day, 50,000 people in the world die from water-borne diseases, many of which occur in developing countries that do not have access to adequate water resources (4). Improving public 
health without achieving Healthy drinking water is not possible. More than 250 million people are infected with water-related diseases each year, leading to 5 to 10 million deaths a year, well above the DALYs. The Centers for Disease Control and Prevention (CDC) reports that 1,020 people in the United States became infected with water-borne diseases in 2001 and 2002. Microbial diseases are one of the most important water-borne diseases that cause the transmission of various diseases in humans. To be. These contaminants may occur directly from drinking contaminated water or from indirect contact (5).

After entering the respiratory system, Legionella can survive and proliferate inside host cells and reaches the target cells mainly by inhalation and aspiration (6). The bacterium is also capable of voluntary intracellular life and can grow and multiply in pulmonary monocytes and macrophages and the cytoplasm of some protozoa such as free amoebae, Acanthamoeba, and Negleria, and after entering the respiratory system through the flagellum. Epithelial cells are attached, the resistance of the organism inside the alveolar macrophages plays an important role in the progression of the disease.

Of the 50 species and 70 identified Serogroups legionella, approximately 20 species are pathogenic to humans (7). Legionella pneumophila itself has 16 different serogroups (8), which is the cause of legionellosis in more than $90 \%$ of cases, and Legionella pneumophila serogroup (SG1) is the cause of $84 \%$ of epidemics and recurrences (9). This bacterium is replaced in the human respiratory tract by inhalation of small water particles carrying the bacterium and leads to infection $(6,10,11)$.

People with immunodeficiency, organ-receiving patients, the elderly, alcoholics, and drug addicts are more likely to develop this type of nosocomial infection. Legionella species cause two types of independent or clinical diseases, including legionellosis and Pontiac fever (a self-limiting disease similar to influenza) $(12,13)$.

This bacterium is found naturally in lakes, rivers, hot springs, swimming pools, water pipes, cooling towers, and ventilation systems. $(8,14)$ Water distribution networks in hospitals are an important source of Legionnaires' disease. (15). This bacterium is a water flora and the ability to survive in waters with different temperatures $\left(0-68{ }^{\circ} \mathrm{C}\right)$ It has a pH of $8-5$ and hot water systems are an ideal environment for the growth of this bacterium. $(16,17)$ The coexistence of Legionella bacteria with algae and other bacteria, especially in the biofilm complex, as well as protozoa, provides the necessary food sources for bacterial survival. (18) Temperature and nutrition have a significant effect. Legionella pneumophila has resistance and distribution in aqueous environments and this bacterium survives for a long time due to its metabolic activity in low-temperature waters. (19).

Aquatic biofilms provide special ecological conditions for the growth and reproduction of Legionella. High temperatures, organic and inorganic substances in water, as well as the presence of protozoa have a major impact on their growth and spread. Some substances, such as plastic faucet gaskets, increase the growth of Legionella. $\square$ Bacteria such as Aeromonas, Mycobacterium, Pseudomonas, and Flavobacterium species, especially in the biofilm complex, provide protection and conditions for the growth and survival 
of bacteria. This relationship creates conditions for the bacterium that can easily resist adverse environmental conditions and disinfection $(20,21)$.

Due to the health problems caused by Legionella and the fact that water in various centers and places is the most important cause of transmission and disease, it is necessary to take effective measures to remove this bacterium from water sources, especially water used in medical centers.

\section{Materials And Methods}

This descriptive cross-sectional study was conducted for three months (from the beginning of autumn to the end of autumn of 2020) in the water supply system of two commercial centers with three different types of piping (George Fischer pipes and fittings, Ray Ho pipe, and ordinary polyethylene). The G1 Center used George Fischer Legionella Stopper pipes and fittings for indoor water supply, the G2 Center used Ray Ho pipes and fittings, and Center No. 3 had regular polyethylene pipes. All three centers were located close to each other and in area one of Tehran Municipality, and due to the lack of distance in the geographical location, the chemical quality of water entering the urban network in both centers was no different. 56 samples ( 36 samples of cold water and 20 samples of hot water) from the gallerycommercial center of Galleria, in which 34 samples of the system with pipes and fittings of George Fischer and 22 samples of the ward equipped with pipes and fittings of Ray Ho, as well as 5 samples of the hospital Taleghani was collected with a conventional metal piping system in sterile containers made of polyethylene with a volume of 1.5 liters from different parts of the office-commercial complex of Taleghani Gallery and Hospital according to Table 2-1 and was collected and analyzed to examine the presence of Legionella.

$3 \%$ sodium thiosulfate was used to remove residual chlorine from water samples. Residual chlorine, $\mathrm{pH}$, and temperature were measured at the sampling site according to standard methods. Samples were immediately transferred to the laboratory in the vicinity of ice boxes for a maximum of 8 hours and concentrated using membrane filtration and vacuum pump (model VE115N) and polycarbonate micron carbon filter (Uflow Membrane Filters, pore size: 0.22-0.45 $\mu \mathrm{m}$ ). An autoclave (temperature $121^{\circ} \mathrm{C}$, pressure $15 \mathrm{ppm}$, and time 15 minutes) was used to sterilize the components of the filtration system. After filtration, the filter was separated and filtered in $50 \mathrm{ml}$ of water and crushed into sterile glass containers, and suspended. To ensure the separation of bacteria from the water filter containing the filter particles was mixed for 24 hours using an orbital shaker (GFL-3017) at a speed of $230 \mathrm{rpm}$ and stored in a refrigerator at $+4^{\circ} \mathrm{C}$ until culture.

\section{Culture}

BCYE agar medium (manufactured by Biomark) contains L-cysteine supplements (manufactured by Merck Germany), pyrophosphate (manufactured by Sigma Aldrich), and GVPC (Glycine, Vancomycin, Polymyxin B, Cycloheximide) (manufactured by Biomark) according to the instructions used for bacterial culture. To ensure the control of other bacteria, the samples were heat-treated using a water bath $\left(56^{\circ} \mathrm{C}\right.$ for 12 minutes) before planting. $100 \mu$ of the sample was inoculated on the culture medium and the 
plates were placed in a candle jar containing 2-5\% carbon dioxide for 7-14 days at $37^{\circ} \mathrm{C}$ in a humid environment (Figure 1). Legionella colonies were identified based on size, color, and biochemical properties (catalase, oxidase, hydrolyze Hippurate, and gram staining tests). To be sure, the grown colonies were re-inoculated on blood agar medium (base material made by German Merck company and Iranian sheep spring defibrinated blood) and incubated at $35^{\circ} \mathrm{C}$ and after ensuring no growth, they were assigned to Legionella was confirmed (22,23). Data were analyzed and reported using Excel 2010 software and descriptive statistics.

\section{Detection of Legionella}

Legionella growth was monitored and recorded on the third, fifth, seventh, tenth, and fourteenth days. The colonies that appear on the first and second days are not Legionella, and the colonies that appear on the third and later days should be thoroughly examined. Also, $0.5 \mathrm{ml}$ of sodium-containing sample was stored in sterile Eppendorf tubes for PCR in a $-70^{\circ} \mathrm{C}$ freezer.

Legionella colonies were detected under ultraviolet light by their size, color, type, and special and their fluorescence properties. In addition, the grown colonies were re-cultured on BCYE agar and their appointment to Legionella was confirmed after ensuring that they did not grow.

Legionella colonies are white-gray or blue-green, convex, shiny with a diameter of 2-4 $\mathrm{mm}$. The central part of the young colonies appears as light gray and granular like a glass background, while the peripheral part of the colony is light pink or blue.

\section{Primer preparation}

To select and design specific primers, some cases should be considered. Due to the diversity of primer sequences, to design the best primer, the sequence of identified genes in genome databases is collected and then analyzed. The primers were compared with the sequences recorded in the Genome Bank (Blast) by a set of analysis programs and sequence comparisons. (Tables 1, 2).

\section{Table1: Sequence of primer for mip gene}

\begin{tabular}{|ll|}
\hline AAAGGCATGCAAGACGCTAT & P: F-mip \\
\hline GTATCCGATTTTCCGGGTTT & P: R-mip \\
& Amplicon size242 bp \\
\hline
\end{tabular}

\section{Table2: Sequence of primer for mip gene}




\begin{tabular}{|ll|}
\hline AGGGTTGATAGGTTAAGAGC & P:F-16srRNA \\
CCAACAGCTAGTTGACATCG & P: R-16srRnA \\
& Amplicon size384 bp \\
\hline
\end{tabular}

\section{DNA extraction}

DNA extraction was performed using a PROMEGA kit.

\section{The quantitative examination of extracted DNA}

In this method, using a spectrophotometer, light absorption of all samples is read at $260 \mathrm{~nm}$, and using the following equation, was obtained the DNA concentration of sample C $(/ \mathrm{g} / \mathrm{ml})=50 \mathrm{~d} . \mathrm{A} 260$.

\section{Gel electrophoresis PCR product}

To view the PCR product, amplicon electrophoresed on agarose gel $1 \% \mathrm{n}$ and observed in the presence of UV light.

\section{Sequencing of 16srRNA and mip gene}

To confirm the genes, the PCR product of each of the mip and 16srRNA genes sent to the pishgam company for sequencing, and the sequence results were BLAST.

\section{Results}

\section{Culture results and diagnostic tests}

Suspected colonies on BCYE agar gram were stained with gram technique. Legionella organisms are gram-negative bacilli with a length of approximately 2-20 $\mu \mathrm{m}$. Catalase and oxidase tests were performed.

\section{Morphology of Legionella}

Legionella is found in fresh culture as bacilli and in old culture as filamentous.

\section{Sodium Hippurate hydrolysis test}

If the bacterium is Legionella pneumophila, it releases the enzyme hypuurase into the medium, which breaks down the Hippurate to glycine and benzoic acid. The addition of ferric chloride reagent results in a reaction between the reagent and benzoic acid and a white precipitate.

By adding Chloride Ferric reagent to the culture medium containing $1 \%$ sodium hypochlorite, the formation of a white precipitate is a positive sign of the test. 


\section{Culture on blood agar medium}

In this experiment, the bacterium was isolated from the suspected colony cultured on BA. After 48 hours of incubation, if the bacteria did not grow in this medium, the test result will be negative for Legionella.

\section{PCR results}

PCR results to identify the Legionella genus performed using 16srRNA.

\section{Mip gene and 16 srRNA sequence results}

The results showed $80 \%$ homology mip gene sequence results

\section{Culture and PCR results in water samples examined for the presence of Legionella}

In this study, a total of 61 samples were collected for Legionella pneumophila. From this number, 34 samples were collected from the northern part of the gallery office commercial, in which George Fischer pipes and fittings were used. A total of 22 samples were collected from the northern part, which used Ray Ho pipes and fittings. Five samples were collected from Taleghani Hospital in which metal pipes and fittings were used. The results showed that George Fischer pipes and fittings have very high efficiency and performance in controlling the growth of Legionella pneumophila.

PCR results showed that out of 61 samples collected, of which 34 samples were related to the George Fischer piping system, 22 samples were related to the Rayho piping system and 5 samples were related to the metal pipe of Taleghani Hospital, $35.2 \%$ of the samples were George Fischer, $45.4 \%$ of Ray Ho samples and $80 \%$ of Taleghani Hospital samples were positive for 16 SrRNA gene. It was also found that $82.3 \%$ of George Fischer samples, $54.5 \%$ of Ray Ho samples, and $20 \%$ of Taleghani Hospital samples were positive based on the mip gene.

\section{Discussion}

The wide and increasing range of Legionella diseases, as well as the isolation and identification of species and serogroups of this bacterium from environmental sources and patients, indicates the global spread of Legionella species in different countries.

Numerous reports of the epidemic and sporadic occurrence of Legionnaires' disease and its resulting deaths have attracted the attention of researchers and specialists in lung and respiratory diseases, infectious diseases, microbiology, immunology, environment, genetics, etc.(12)

Early diagnosis of Legionellosis and epidemiological conditions in the hospital is necessary not only for correct and effective treatment but also to control and prevent the subsequent onset of the disease. It seems that due to the high mortality rate of Legionella disease, more effective measures should be taken to prevent the spread of Legionella species from the hospital environment to patients susceptible to infection. $(7,12)$. 
Legionella infections in immunocompromised individuals, corticosteroid recipients, organ transplants, the elderly and children, alcohol and drug addicts, smokers, patients with diabetes mellitus, underlying diseases, chronic obstructive pulmonary disease, intubation, intubation and it poses a serious threat to heart patients more than anyone else.

Legionella alone causes a high percentage of nosocomial pneumonia. This bacterium causes 1 to $40 \%$ of hospital-acquired pneumonia. The mortality rate in legionellosis is $5-30 \%$. About $5 \%$ of cases of Legionnaires' disease are reported from hospitals. (26)

Legionella pneumophila was the cause of $3.8 \%$ of fatal cases of nosocomial pneumonia. Bacteria of the Legionella genus are isolated from natural water sources, public water reservoirs, water pipes, and even bath showers.

Because various factors are effective in the growth and pathogenicity of Legionella bacteria, the factors affecting the growth and survival of bacteria can be largely identified and their findings can be used to design an appropriate control method. $(! 2,7,26)$

Today, various methods to control Legionella in hospital and community aquatic environments are being studied and performed. Therefore, identifying pathogenic strains in that area can provide specific ideas for the use of effective and efficient disinfectants to control Legionella.

In a hospital population, there are always patients who are susceptible to infection and are at high risk for Legionella. Water is one of the common sources of Legionella transmission in hospitalized patients.

Early diagnosis of legionellosis and epidemiological conditions in the hospital is necessary not only for correct and effective treatment but also to control and prevent the subsequent onset of the disease. It seems that due to the high mortality rate of Legionella disease, more effective measures should be taken to prevent the spread of Legionella species from the hospital environment to patients susceptible to infection. (12)

Many types of research have been done using different methods in removing Legionella from water, some of which are mentioned, and the advantages and disadvantages of this research are examined.

Loret et al. reported in 2005 studying a variety of disinfectants such as ozone, chlorine dioxide, chlorine, monochloramine, and copper and silver ionization to remove amoebae and plankton. Marches et al. Chlorine oxide was used to remove Legionella bacteria (24). Sodium hypochlorite was used to remove Legionella from water, which of course has a higher oxidation rate than other disinfectants and affects a wide range of microorganisms, but has disadvantages such as carcinogenicity and side effects (26).

Other methods used to remove Legionella bacteria were photocatalytic oxidation (using $365 \mathrm{~nm}$ UV) with titanium dioxide. Chen et al. used the heat shock method in 2005. 
In a 2008 study by Cheng et al., They used the ionization process of copper and silver as a disinfectant to remove Legionella pneumophila. This procedure took 4 to 7 months and studies have shown that this method is effective in the short term and the pollution has not been eliminated (27).

Diamond electrode electrolysis is used to remove and inactivate Legionella bacteria (28).

In general, the advantages of this research over other research in this field are as Long-term bactericidal stability of George Fischer tube, do not use chemicals, No carcinogenicity, No corrosion of pipes, No side effects, No need for preparation, Low investment cost.

The results showed that George Fischer pipes and fittings are much less contaminated and only out of 34 samples related to the George Fischer pipe and fittings system, 2 samples (samples number (20 and 10) showed contamination with Legionella, based on which it can be said that the pipe and George Fischer connections in more than $95 \%$ of the growth of Legionella pneumophila in water, which showed the role and impact of using this system in controlling infections associated with this bacterium, which causes very acute and important problems in the health system, especially in Medical centers, hotels and other administrative, commercial and recreational centers, so that in case of contact with this bacterium and infection and lack of proper treatment can cause the death of infected people.

The results showed that the use of Ray ho pipe and fittings system has higher contamination than George Fischer pipe and fittings system, so that out of 22 samples collected from Ray ho pipe and fittings, 12 samples showed positive and Legionella contamination. These results showed that Ray ho pipes and fittings in more than $55 \%$ of Legionella contamination, which confirms the superiority of George Fischer pipes and fittings over Ray ho pipes and fittings.

Examination of the results in terms of Legionella bacterial density in these systems also shows that George Fischer pipes and fittings are not only less contaminated but also in terms of contamination density than Ray ho pipes and fittings and metal pipes. As the system in George Fischer pipes and fittings, only 2 samples with 2 bacteria per liter of water have been observed, while in Ray ho and metal pipes, the probability of contamination and bacterial density is high, which indicates a good ability George Fischer pipes and fittings are in control of Legionella and the inability of these pipes to control Legionella.

The results showed that the average bacterial density in Ray ho pipe and fittings was more than twice that of George Fischer pipe and fittings, so that the range of changes in Legionella bacterial density in Ray ho pipe and fittings was in the range of 2-16 colonies per liter, while this density in pipe George Fischer's connections are only 2 bacteria per liter, which is even lower than the recommended standards for Legionella density in the piping system of developed countries. Comparison of Legionella density in metal pipes also shows that these pipes are not comparable to George Fischer pipes in terms of both probabilities of contamination and density so that in these pipes, 3 out of 5 samples had contamination in which bacterial density. On average, there are more than 43 colonies per liter of water. 
The presence of positive results and densities of Legionella bacteria in water samples and their negation in PCR method based on mip gene indicates the presence of contaminants in water that contact with the pipe fittings of George Fischer has prevented its growth or caused their destruction. The only evidence of the presence of Legionella pneumophila DNA in water, which confirms the effect of George Fischer pipes and fittings in controlling and removing Legionella, which shows that this system is suitable for use in the plumbing of medical centers, hotels, leisure centers, etc. Because in such centers, people are more likely to be exposed to acquired lung pneumonia, which not only has a high cost of treatment but also causes death if not treated properly. The results showed that 28 of the 34 samples of George Fischer pipes and fittings in the culture method were negative but based on positive mip gene, which indicates the absence of culturable bacteria but also shows the presence of Legionella pneumophila DNA as a dangerous species of Legionella in water and ability the effect of the tube on the control of Legionella. This is the case for 6 out of 22 Ray ho pipes and fittings.

\section{Abbreviations}

Gorge Fischer plumbing system:

Unique properties of polybutylene pipes in the IFIT system All-plastic polyethylene pipes used in the latest building plumbing system, or IFIT system, are produced exactly in accordance with BS 15876 standard.

PCR: Polymerase chain reaction

Legionella Pneumophila:

Legionella pneumophila is a thin, aerobic, monotrichous, flagellated, Gram-negative bacterium and is legionellosis agent.

\section{Declarations}

Ethics approval and consent to participate Not applicable. Consent for publication All of the authors agree with publication manuscript. Availability of data and materials All data generated or analyzed during this study are included in this published article and are available from the corresponding author on reasonable request. Funding The authors don't receive funding for this research. Authors' contributions All authors read and approved the final manuscript. Declaration of competing interest The authors declare that they have no competing interests. Acknowledge: We thank the Iranian Plumbing Systems Technology Development Company as the only representative of the Swiss company George Fischer in Iran.

\section{References}

1. Li Z, Boyle F, Reynolds A. Rainwater harvesting and greywater treatment systems for domestic application in Ireland. Desalination. 2010;260(1):1-8. 
2. Craun MF, Craun GF, Calderon RL, Beach MJ. Waterborne outbreaks are reported in the United States. J Water Health. 2006;4(Suppl 2):19-30.

3. Bartram J, Cairncross S. Hygiene, sanitation, and water: forgotten foundations of health. PLoS Med. 2010;7(11):e1000367.

4. Fields BS, et al. Legionella, and Legionnaires' disease: 25 years of investigation. Clinical microbiology reviews;. 2002;15(3):506-26.

5. Bagheri H, Khaledi A, Ghanizadeh G, Esmaeili D. Efficacy of PCR Analysis of Mip, Doth and Gspd Genes with Culture in Detection of Legionella pneumophila. Iran J Public. Iran J Public Health, Vol. 50, No.5, May 2021, pp.1079-1081.

6. Mirkalantari S, et al. Isolation of Legionella from BAL samples of Legionella pneumonia patients, by PCR and Culture Methods." Pathobiology Research.2008;10: 75-83.

7. Ghanizadeh G, Gholinezhad M, Khaledi A, Esmaeili D. Heterogeneous catalytically ozonation as a novel disinfectant for inhibition of Legionella pneumophila virulence. Gene Reports.2019; 17;100534.

8. Evans IA, MarichAJ, Harding P. Bug Breakfast in the Bulletin: Legionnaires. N S W Public Health Bull. 2008;19(8):146.

9. Safaee M, Ghanizadeh G, Esmaeili D. Application of ozonation process for the removal of Legionella pneumophila from water. J Kermanshah Univ Med Sci. 2015;19(4):197-206.

10. Khaledi A, Bahrami A, Nabizadeh E, Amini Y, Esmaeili D. Prevalence of Legionella Species in Water Resources of Iran: A Systematic Review and Meta-Analysis. IJMS.

11. Vol 43, No 6, November 2018.

12. Farhat $M$, Moletta-Denat $M$, Frère J, Onillon $S$, Trouilhé M-C, Robine E. Effects of disinfection on Legionella spp., eukarya, and biofilms in ahot water system. Appl Environ Microbiol. 2012;78(19):6850-8.

13. Khaledi A, Bahrami A, Nabizadeh E, Amini Y, Esmaeili D. Prevalence of Legionella Species in Water Resources of Iran: A Systematic Review and Meta-Analysis. Iran J Med Sci. 2017;1-10.

14. Ghanizadeh G, Mirmohammadlou A, Esmaeli D. Predictive Parameters of Heterotroph Plate Count Bacteria Amplification in Hospital Water Lines. JOURNAL OF PURE AND APPLIED MICROBIOLOGY.2015. Vol. 9(2), p. 1007-1013.

15. Carratala J, Garcia-Vidal C. An update on Legionella. Curr Opin Infect Dis. 2010;23(2):152-7.

16. Mirmohammadlo A, et al. (2014). "Legionella pneumophila water contamination in three military hospitals of Tehran in 2013."JOURNAL OF KERMANSHAH UNIVERSITY OF MEDICAL SCIENCES.2014: 18 (7); e74079.

17. Allen JG, Myatt TA, Maclntosh DL, Ludwig JF, Minegishi T, Stewart JH, et al. Assessing risk of health care-acquired Legionnaires' disease from environmental sampling: The limits of using a strict percent positivity approach. Am J Infect Control. 2012;40(10):917-21.

18. Singh $T$, Coogan M. Isolation of pathogenic Legionella species and legionella-laden amoebae in dental unit waterlines. J Hosp Infect. 2005;61(3):257-62. 
19. Bartram J. Legionella and the prevention of legionellosis. World Health Organization; 2007.

20. Gholinezhad M, Esmaeli D, Ghanizadeh G. Inhibition of T4ss Gene Legionella pneumophila with Catalytical Ozonization. JOURNAL OF PURE AND APPLIED MICROBIOLOGY.2015. Vol. 9(Spl. Edn. 2), p. 437-441.

21. Pankhurst C, Philpott-Howard J, Hewitt J, Casewell M. The efficacy of chlorination and filtration in the control and eradication of Legionella from dental chair water systems. J Hosp Infect. 1990;16(1):9-18.

22. Chen Y, Lin Y, Liu Y-C, Huang W, Shih H, Wann S, et al. Efficacy of point-of-entry copper-silver ionization system in eradicating Legionella pneumophila in a tropical tertiary care hospital: implications for hospitals contaminated with Legionella in both hot and cold water. J Hosp Infect. 2008;68(2):152-8.

23. Eslami A, et al. Presence of Legionella pneumophila and environmental factors affecting its growth, in the water distribution system in Taleghani hospital. Tehran" Pajoohandeh Journal. 2012;17(1):327.

24. Ghanizad G, Mirmohhamadloo A, Esmaili D. Predictive parameters of Legionella pneumophila occurrence in hospital water: HPCs and plumbing system installation age. Environ Monit Assess. 2016;188(9):536. DOI:10.1007/s10661-016-5554-2.

25. Campos C, Loret J, Cooper A, Kelly R. Disinfection of domestic water systems for Legionella pneumophila. Journal of Water Supply: Research \& Technology-AQUA. 2003;52(5).

26. Hosseini Doust R, Mohabati Mobarez A, Esmaeili D. Detection of Legionella in Hospital Water Supply using Mip Based Primers. Journal of Biological Sciences.2008; Volume: 8 | Issue: 5 | Page No.: 930934.

27. Ghanizadeh G, Mirmohammadlou A, Esmaeili D. Survey of legionella water resources contamination in Iran and foreign countries: A Systematic Review. Iran J Med Microbiol: Volume 9, Number 4 (022016).

28. Hsu B-M, Chen $\mathrm{C}-\mathrm{H}$, Wan $\mathrm{M}-\mathrm{T}$, Cheng $\mathrm{H}-\mathrm{W}$. Legionella prevalence in hot spring recreation areas of Taiwan. Water Res. 2006;40(17):3267-73.

29. Gholinezhad M, Esmaeli D, Ghanizadeh G. Inhibition of T4ss Gene Legionella pneumophila with Catalytical Ozonization. JOURNAL OF PURE AND APPLIED MICROBIOLOGY; Nov 2015.

\section{Figures}




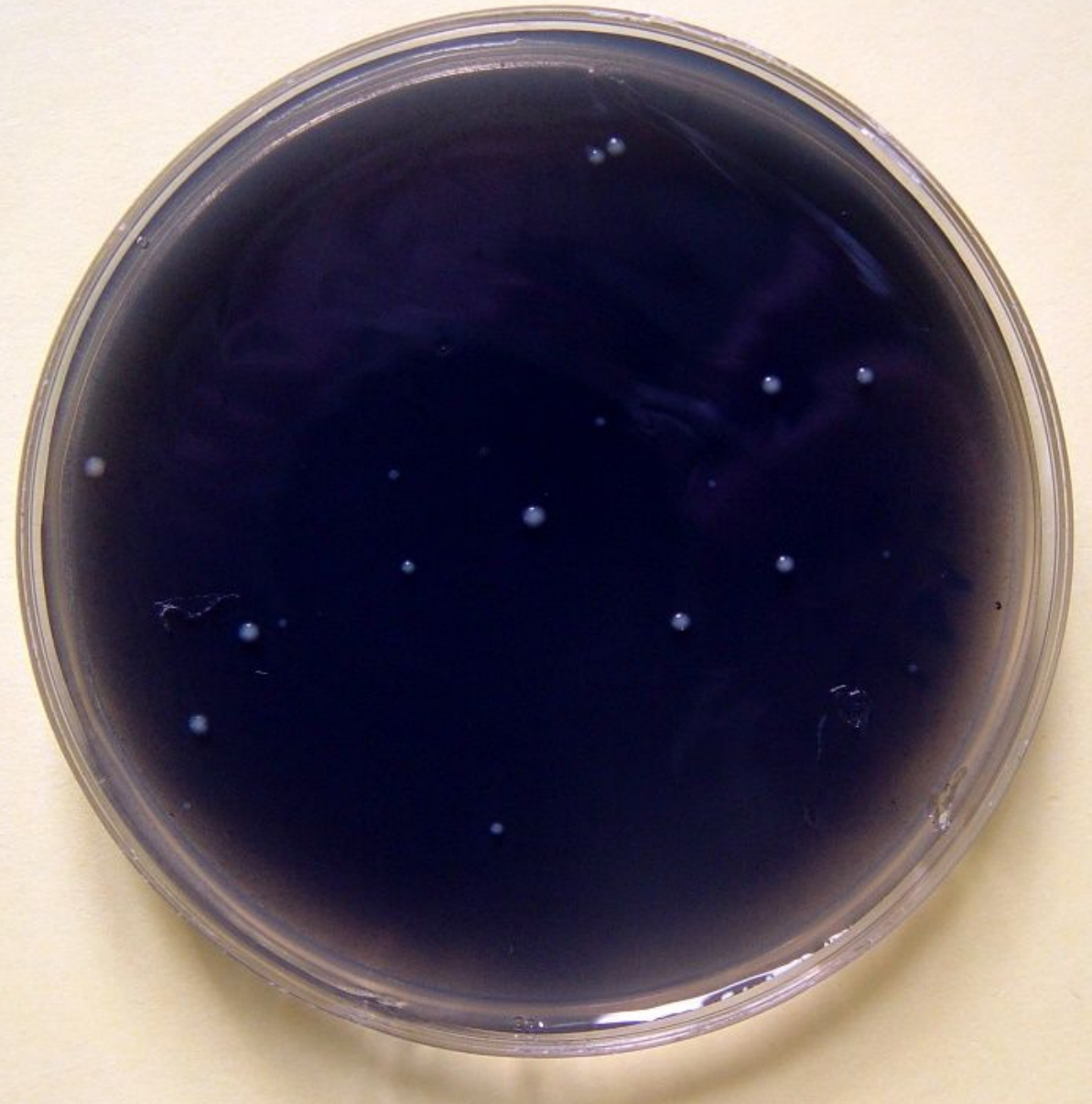

Figure 1

Image of Legionella culture on BCYE agar.

A

B

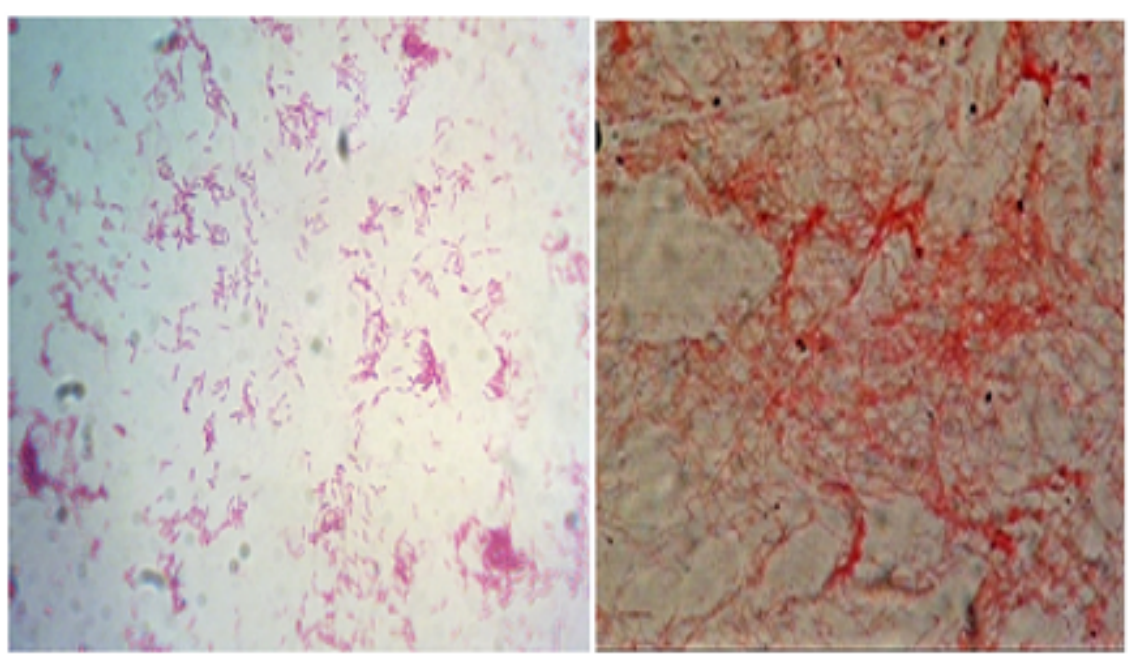

Page $13 / 19$ 
Figure 2

Image A is primary culture and image B is old culture.

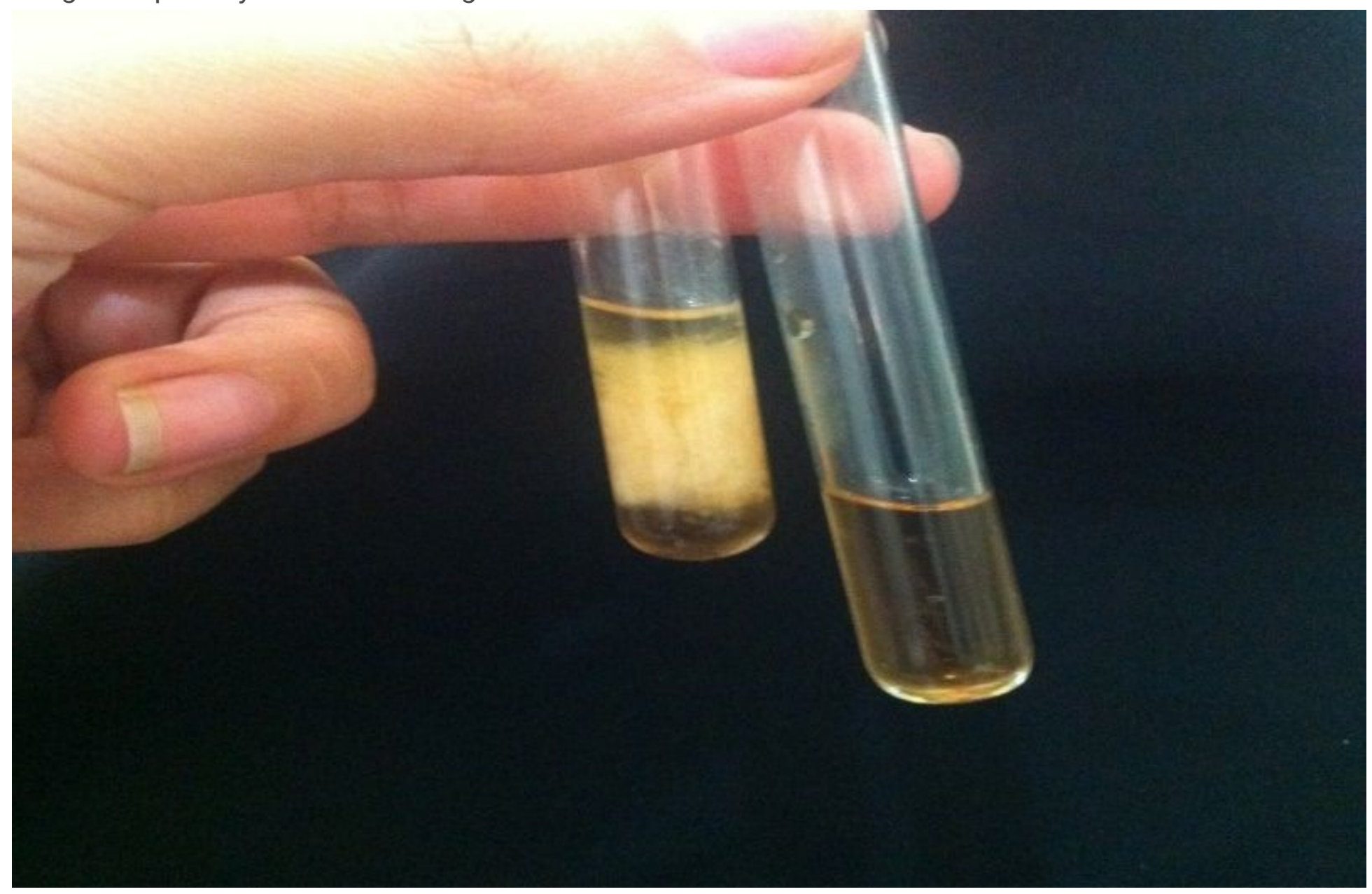

Figure 3

Sodium Hippurate hydrolysis test to confirm Legionella pneumophila.

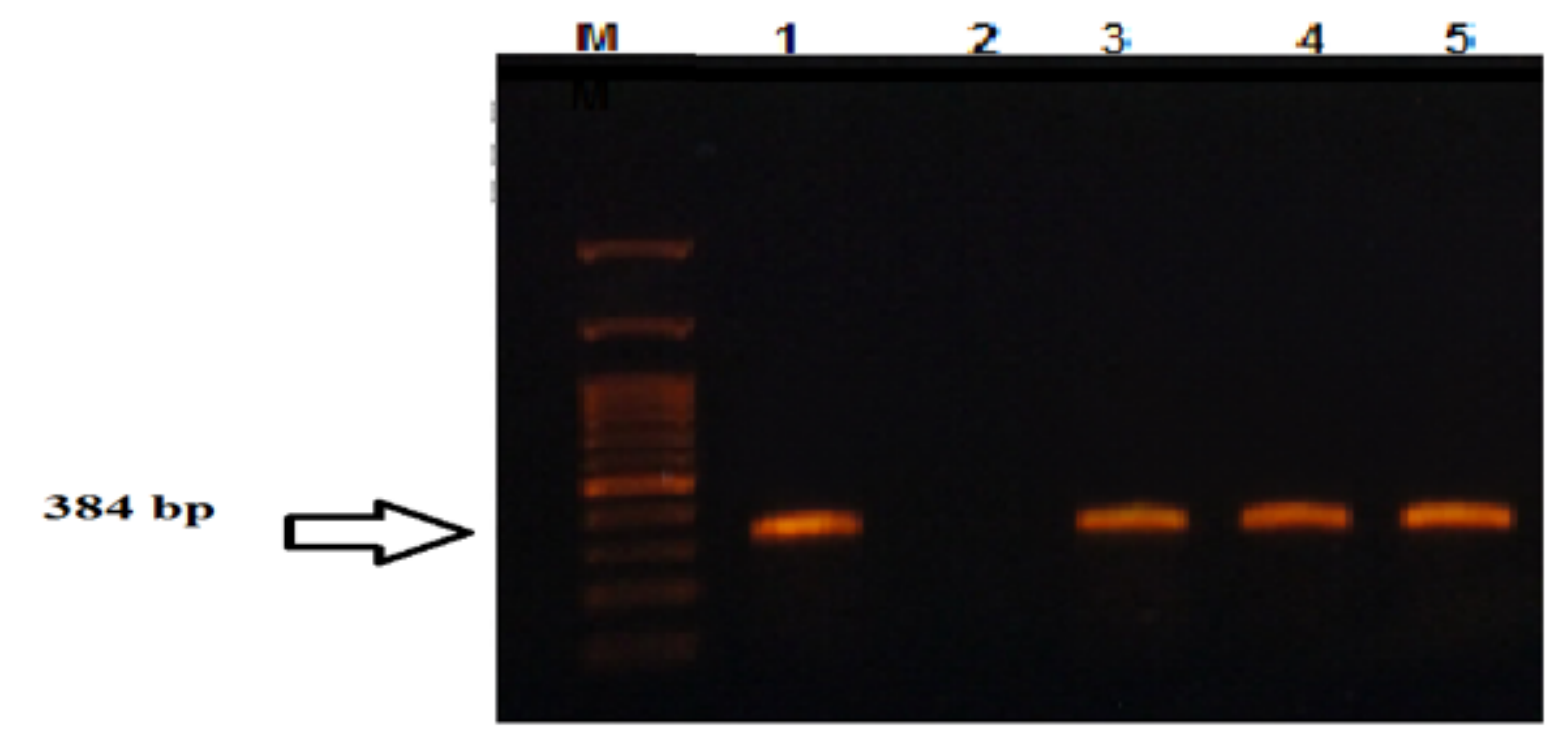




\section{Figure 4}

PCR results to identify Legionella genus with amplicon size $384 \mathrm{bp}$. Well No. 2 Negative control samples and wells No. 1, 3, 4, 5, 6, 7, and 8 test samples of Legionella pneumophila with 16 s rRNA gene.

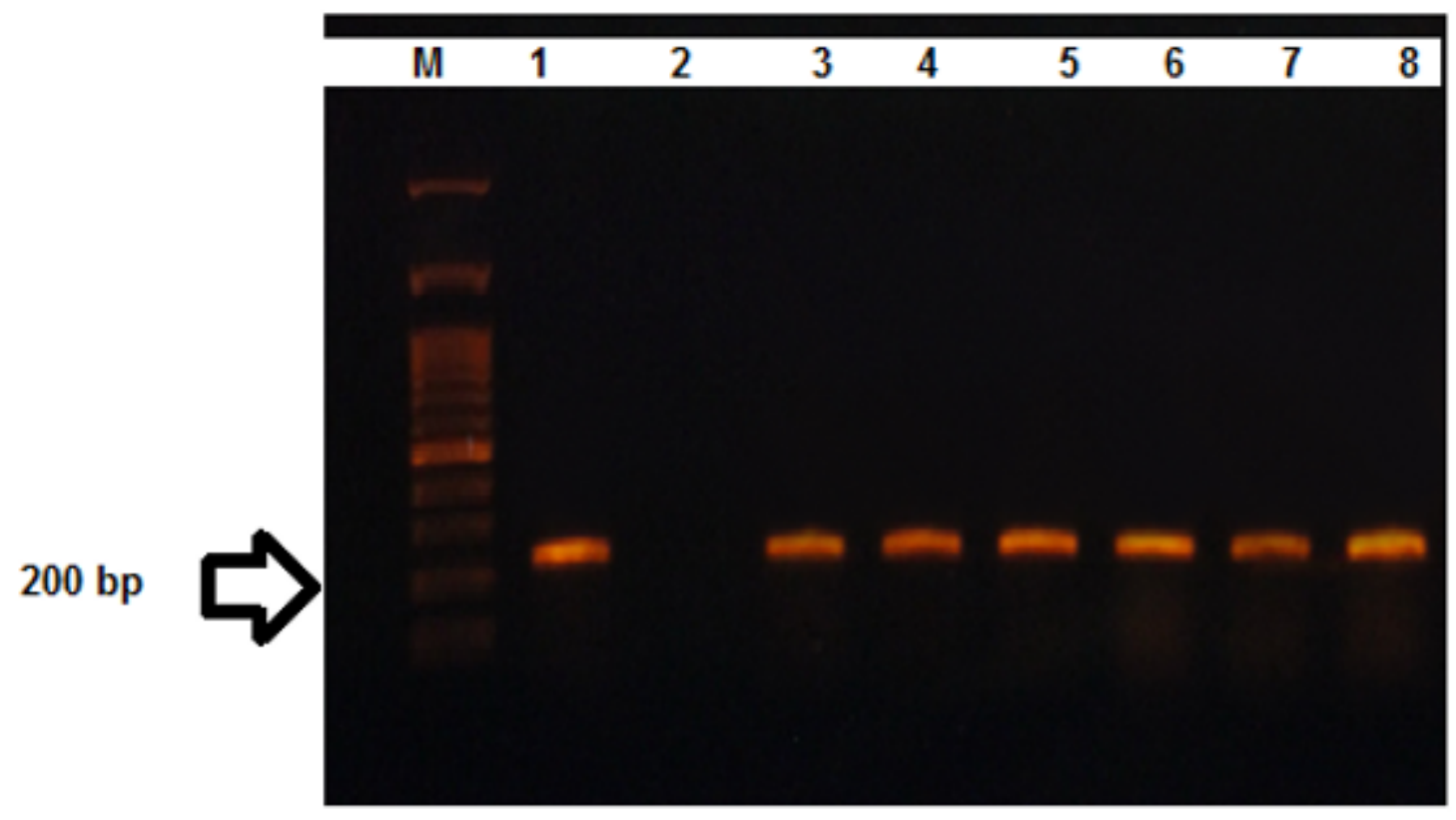

Figure 5

PCR results of Legionella penomophila mip gene: well 1 positive control sample and well 2 negative control sample, wells 3 to 8 positive test samples with amplicon size $384 \mathrm{bp}$. 
Previous Next $\mid 9$ Options -

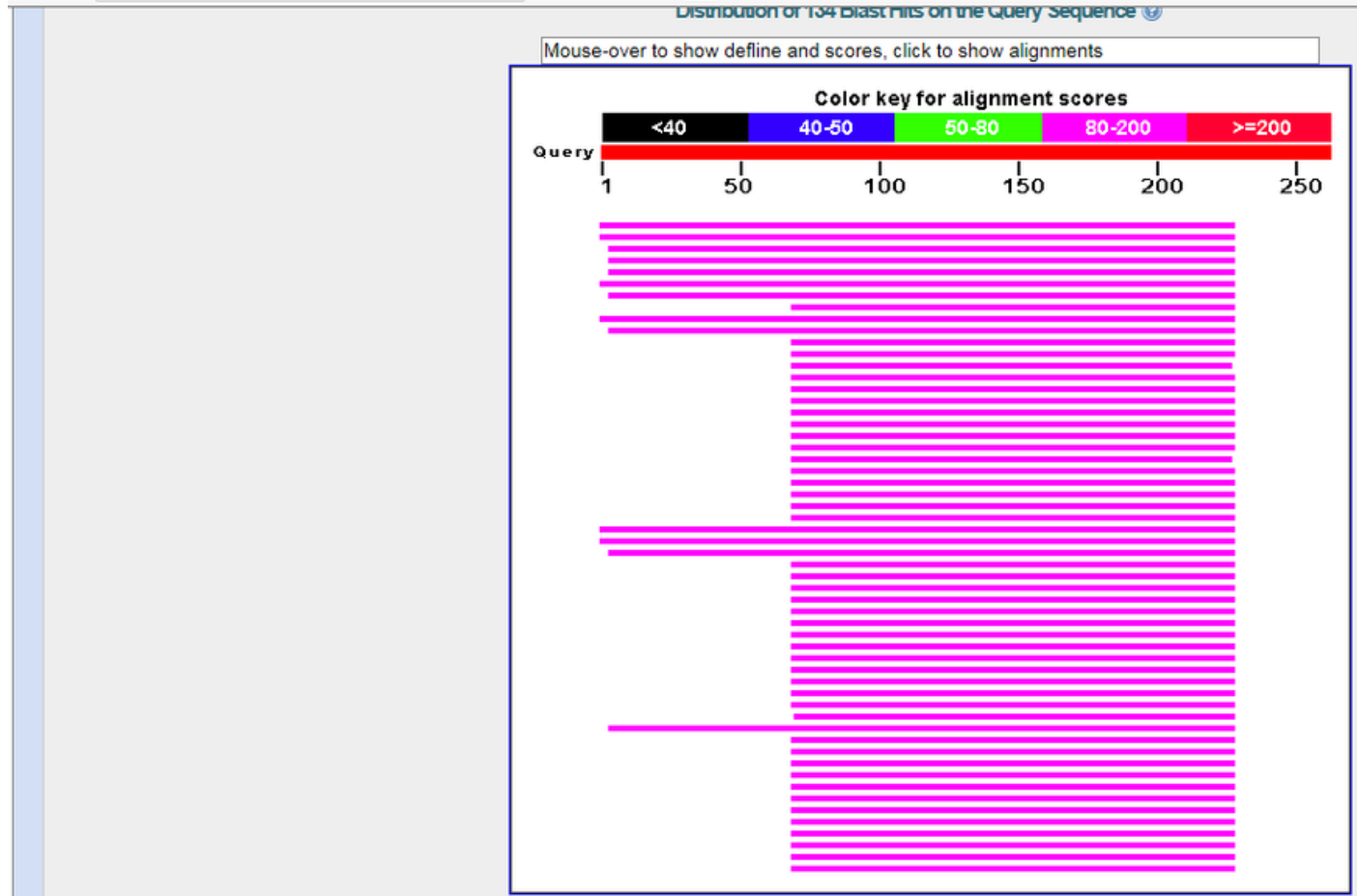

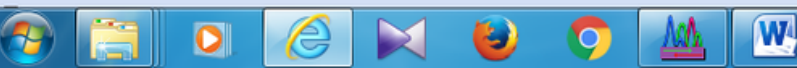

\section{Figure 6}

BLAST sequenced mip gene results.

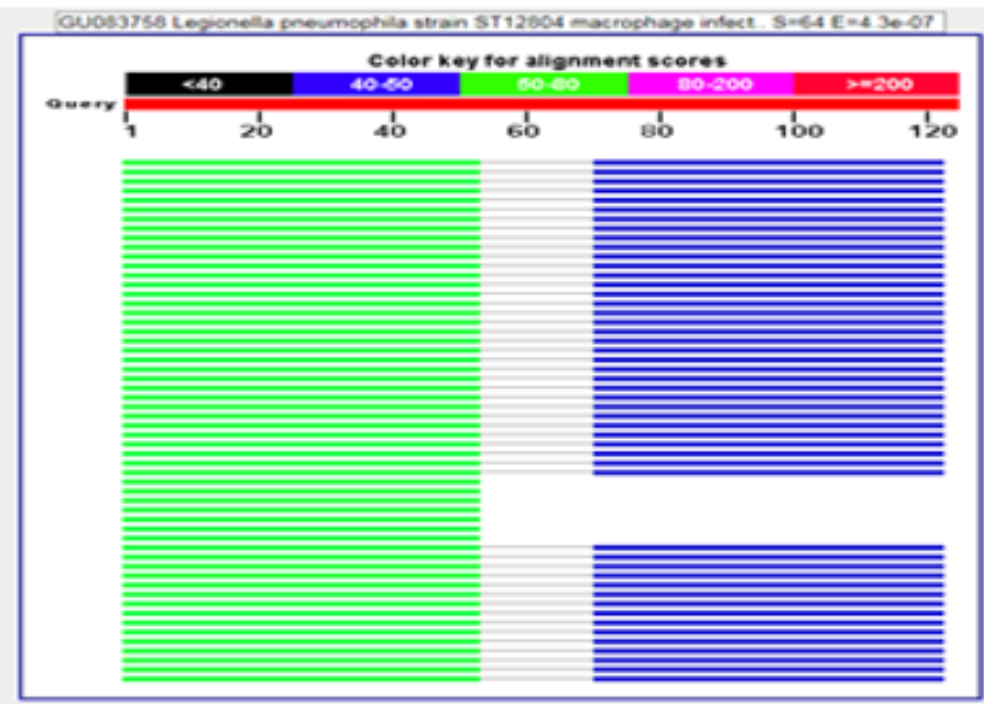

Figure 7

BLAST sequenced 16srRNA gene results 


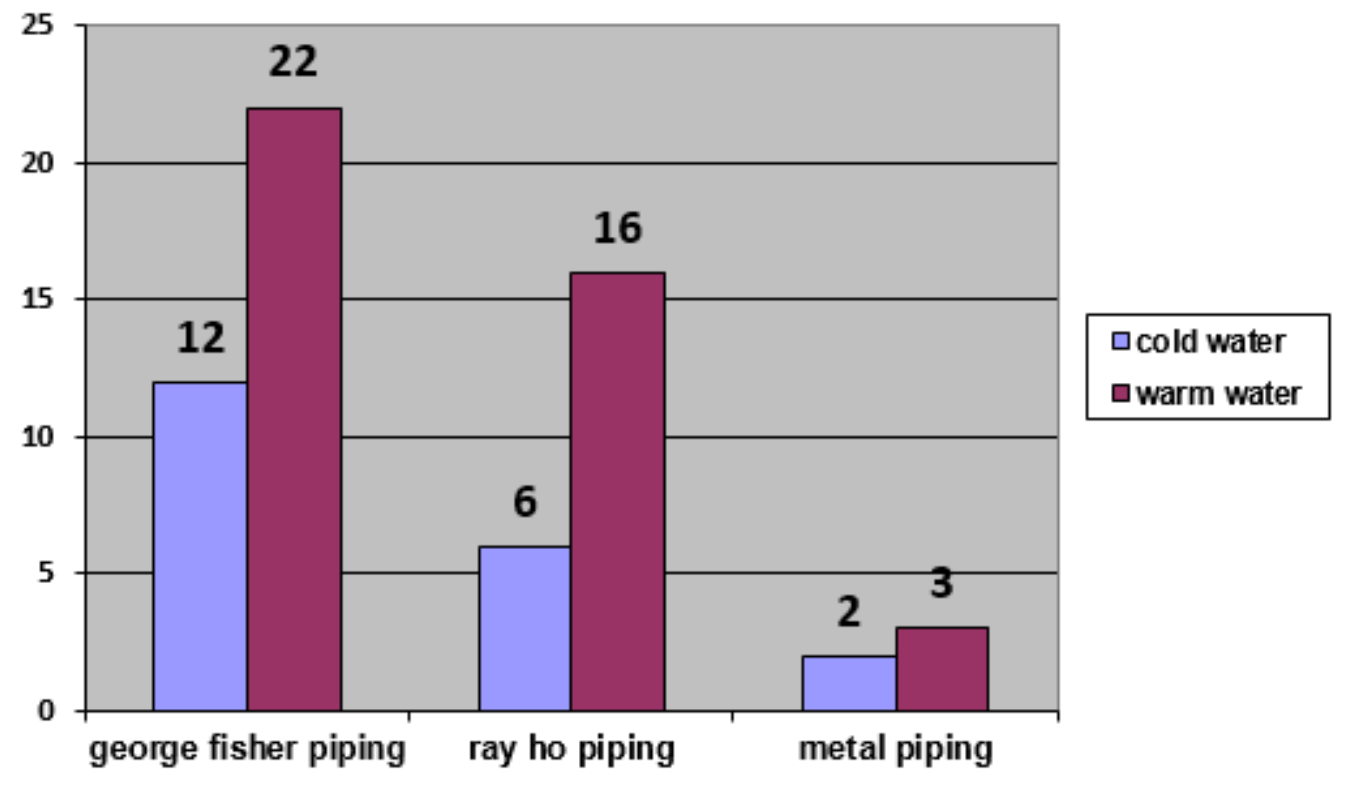

Figure 8

Total number of samples collected from hot and cold-water systems of George Fischer piping system, Ray Ho piping system, and metal pipe.

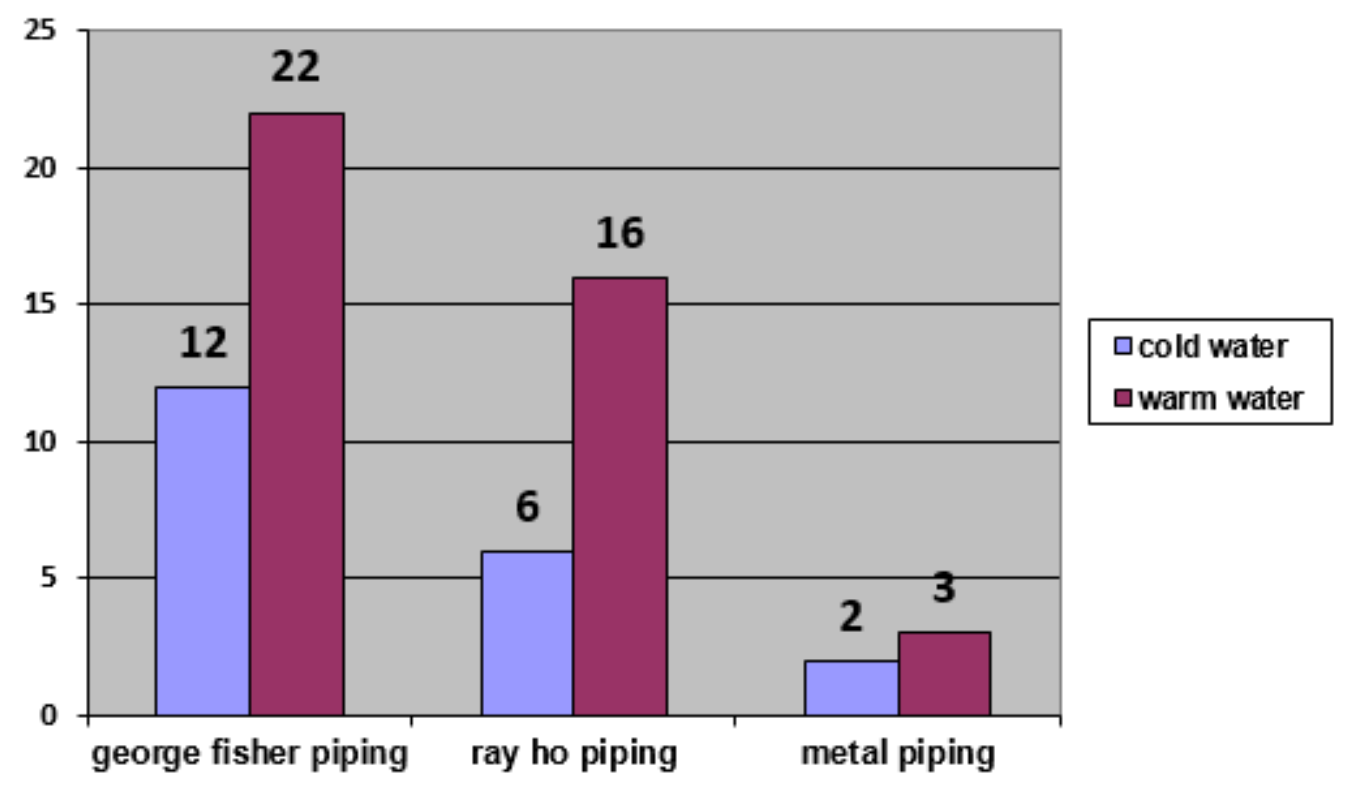

Figure 9

Total number of samples collected from hot and cold-water systems of George Fischer piping system, Ray Ho piping system, and metal pipes. 


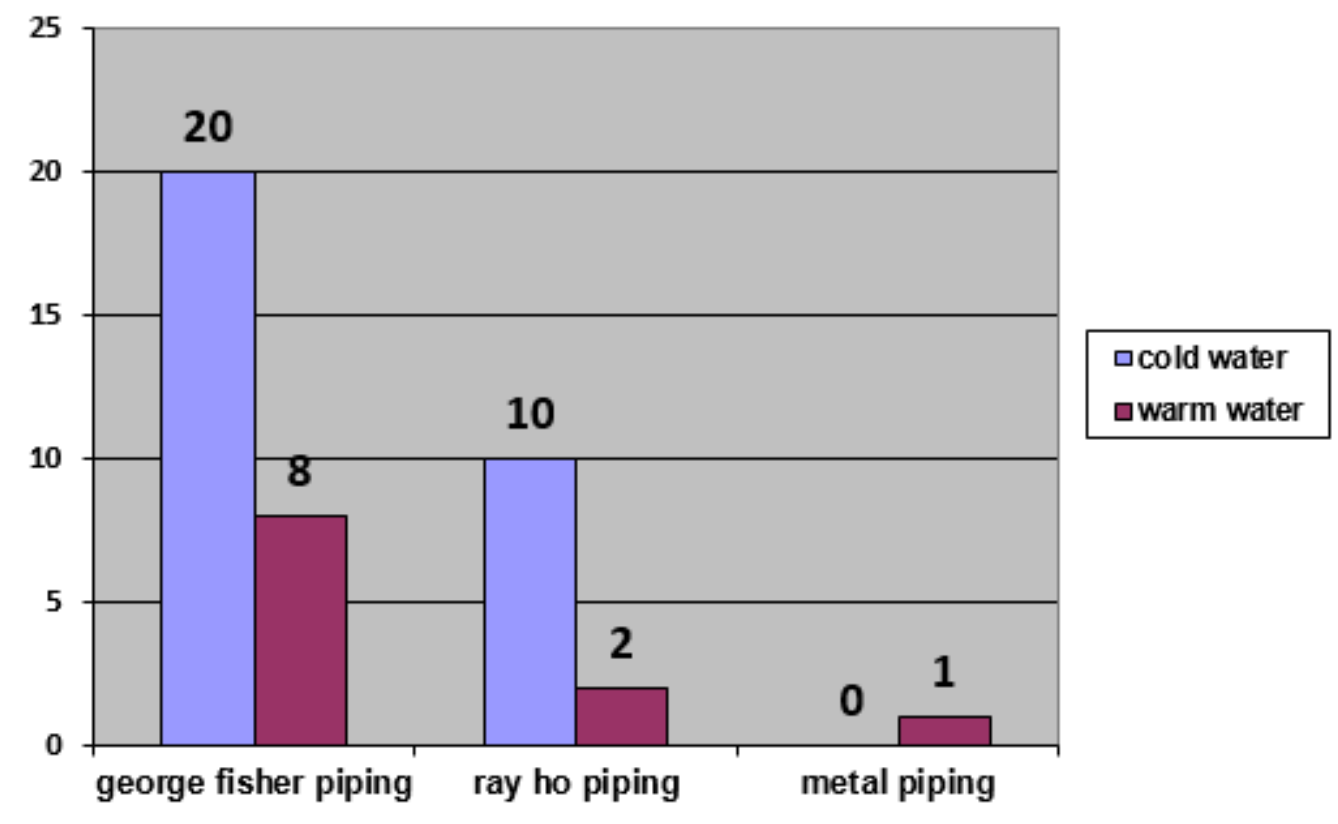

Figure 10

PCR results of cold and hot water samples based on Mip Gene

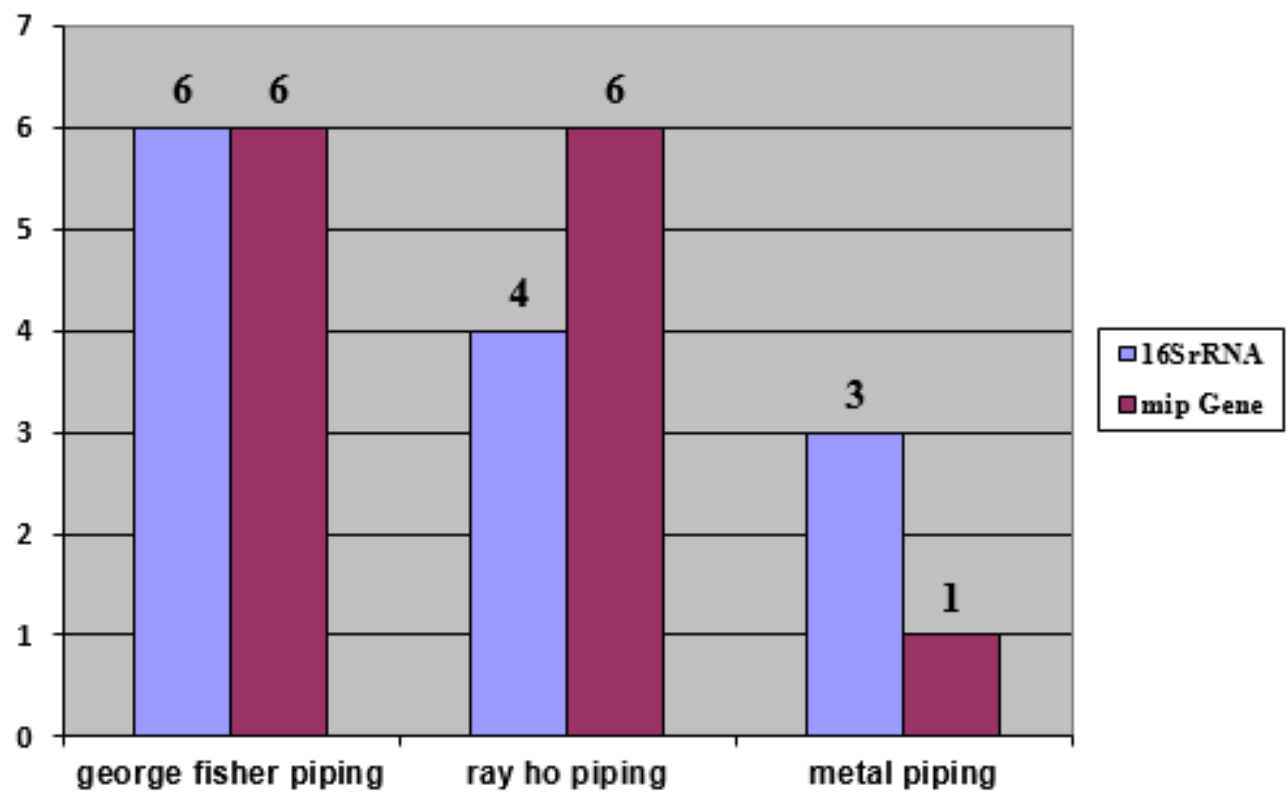

Figure 11

PCR results of cold and hot water samples based on 16SrRNA gene 


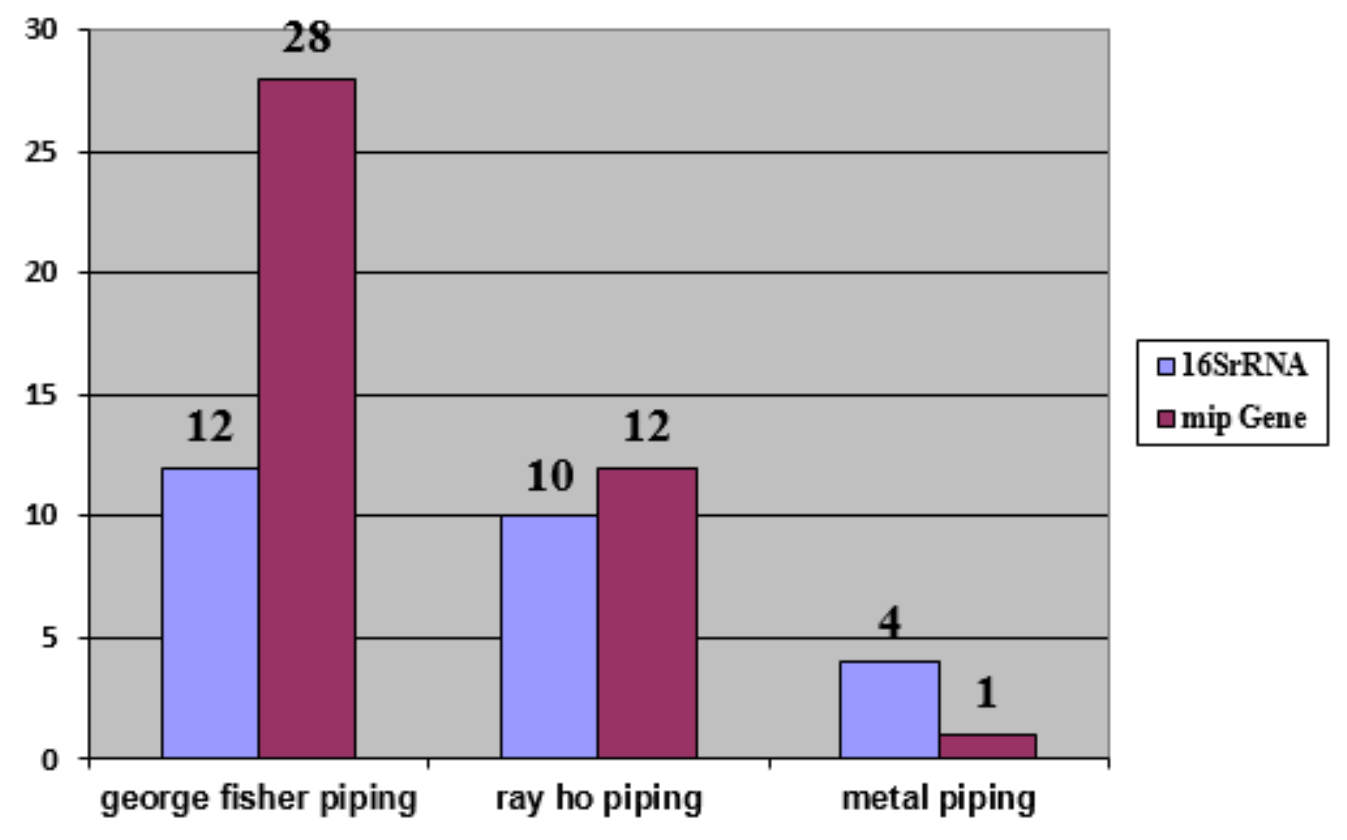

Figure 12

Comparison of mip and 16srRNA gene results in George Fischer, Ray Ho, and metal piping systems. 